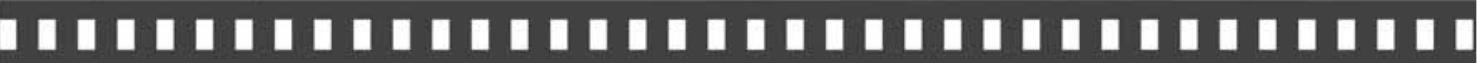

Da imagem ao processo: a produção

e a fruição fotográfica no Arquivo Pedro Meyer

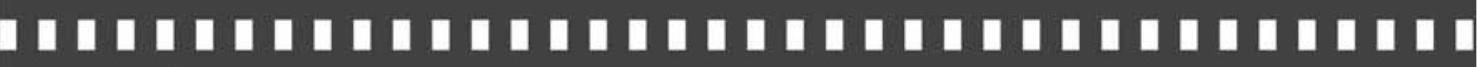

Ana Carolina Lima Santos

Artigo recebido em: 13/07/2015

Artigo aprovado em: 07/09/2015 


\title{
Da imagem ao processo: a produção e a fruição fotográfica no Arquivo Pedro Meyer
}

\author{
From an image to its process: \\ the photographic production and fruition in Pedro Meyer's Archive
}

\author{
Ana Carolina Lima Santos *
}

\begin{abstract}
Resumo: O Arquivo Pedro Meyer é uma plataforma digital na qual todo o trabalho fotográfico do artista, além de textos e vídeos sobre ele, está disponivel sem qualquer filtro do produtor. O presente artigo se propõe a apresentar esse banco de dados bem como a refletir sobre as implicações que ele traz para a circulação, a difusão e a recepção das imagens de Meyer. Por meio de análises documentais e pesquisas bibliográficas, compreende-se que, ao tornar visiveis seus métodos de produção, o fotógrafo revela uma forma autêntica de lidar como sua criação, entendida não como produto final, mas como algo inacabado e incompleto. Além disso, na medida em que dá ao espectador a chance de entrar nos bastidores de sua obra, olhando-a 'de dentro', Meyer permite que ele também passe a entendê-la reintegrada e ressignificada pelos seus processos de fabricação.
\end{abstract}

Palavras-chave: Pedro Meyer; acervo fotográfico; processos de criação; circulação, difusão e recepção de imagens.

\begin{abstract}
Pedro Meyer's archive is a digital platform in which all the photographic work of the artist, as well as documents and videos about it, is available without filters from the producer. The present paper aims to present this database and to reflect on the implications that it brings to circulation, dissemination and reception of Meyer's images. By making visible his methods of production, the photographer seems to reveal an authentic way to deal with his creation, understood not as a final product, but as something unfinished and incomplete. Moreover, Meyer gives the spectator a chance to 'get behind the scenes' to view images reinstated and re-signified by their manufacturing processes.
\end{abstract}

Keywords: Pedro Meyer; photographic collection; creation processes; circulation, dissemination and reception of images.

* Professora do curso de Jornalismo da Universidade Federal de Ouro Preto. Doutora em Comunicação Social pela Universidade Federal de Minas Gerais, mestre em Comunicação e Cultura Contemporâneas pela Universidade Federal da Bahia e graduada em Comunicação Social - Bacharel em Jornalismo pela Universidade Federal de Sergipe. 


\section{Introdução}

Pedro Meyer, fotógrafo espanhol naturalizado mexicano, é uma das figuras mais importantes da história da fotografia latinoamericana. Para além do seu trabalho como produtor de imagens, Meyer assumiu um papel de liderança local entre as décadas de 1970 e 1980 - como fundador do Conselho Mexicano de Fotografia e como principal organizador dos Colóquios Latinoamericanos de Fotografia e das Mostras de Fotografia Latinoamericana. Seu empreendedorismo, nesse campo, levou-o ainda a lançar, em 1995, o ZoneZero (zonezero.com), um portal dedicado à fotografia que até hoje disponibiliza exibições virtuais de fotógrafos de todo mundo e textos assinados por artistas, curadores, críticos e outros colaboradores.

Paralelamente, no âmbito da prática, Meyer enveredou de forma pioneira na descoberta do potencial expressivo do digital. Ainda na década de 1980, ele montou um estúdio equipado com os mais recentes aparatos informáticos, fazendo nele experimentações com as novas tecnologias. Delas surgiu, em 1991, I photograph to remember, referenciado como o primeiro CD-ROM de arte do mundo no qual fotos e sons foram mesclados. Alguns anos depois, em 1995, ele publicou o livro Truths \& fictions, que é creditado como livro inaugural da fotografia digital no continente.

Em 2004, dando continuidade à sua exploração das novas tecnologias, Meyer se propôs a um projeto ambicioso, Herejias. Para essa empreitada, foi montado um banco de imagens virtual com todas as fotografias até então produzidas por ele. As imagens mais antigas foram capturadas digitalmente por scanner e juntadas às já feitas por meios digitais, para que pudessem ser tratadas e catalogadas. Aos poucos, com esse material organizado, ele o disponibilizou, por meio de um site (archivo.pedromeyer.com), com a intenção de que alguns curadores, espalhado por todo o mundo, 
pudessem acessá-lo para que cada um deles organizasse retrospectivas da sua carreira, a partir de diferentes perspectivas. Como resultado desse esforço coletivo, em 2008, o fotógrafo realizou uma exposição com mais de sessenta exibições paralelas em dezessete países - que seriam parcialmente compiladas e publicadas em um livro homônimo, com versões impressa e digital.

Encerrado o projeto, Meyer resolveu ampliar a ideia do banco de imagens, transformando-o em uma base de dados bilíngue (em espanhol e inglês), a que chamou de Arquivo Pedro Meyer. Fotografias, fotolivros publicados, catálogos de exposição, revistas, artigos de jornais, vídeos das mais diferentes procedências e tudo mais que ele reuniu sobre seu próprio trabalho foi disponibilizado, integralmente, em uma plataforma acessível de qualquer computador, celular ou outro dispositivo eletrônico conectado à internet. Para entrar no arquivo é preciso fazer um cadastro gratuito, sujeito a aprovação da equipe que o administra. Desde que justificada a intenção de pesquisa fotográfica, o login é liberado em poucos dias. Dessa maneira, curadores, críticos, acadêmicos, artistas e outros interessados têm a chance de conhecer o acervo do fotógrafo em um estado bruto, sem filtro do produtor ou de terceiros. Igualmente, tem-se a oportunidade de ter acesso a outros materiais produzidos por ou sobre Meyer, em texto e vídeo.

Partindo da experiência pessoal que a autora deste artigo teve com tal base de dados ${ }^{1}$, o presente paper se propõe a apresentá-la e discuti-la no que diz respeito à circulação, à difusão e à recepção do trabalho do fotógrafo por ela possibilitada. Além da análise documental de materiais do arquivo, uma pesquisa bibliográfica sobre questões que o cercam foi realizada a fim de entender melhor as particularidades do banco de dados, bem como as implicações envolvidas na sua publicização. Dois pontos interessam em

Entre 2010 e 2014, a autora passeou pelo Arquivo Pedro Meyer, coletando informações para a tese "Da inter-relação entre fotodocumentário e fotomontagem: a experiência de Pedro Meyer em Truhts \& Fictions", defendida junto ao Programa de Pós-Graduação em Comunicação Social da Universidade Federal de Minas Gerais, sob orientação de César Guimarães e coorientação de Anna Karina Bartolomeu. 
particular: o modo como a revelação das etapas de produção das fotografias, realizada no arquivo, indica uma posição de Meyer em relação à sua obra, entendida como potencialmente provisória, e a forma como isso convoca do espectador uma fruição processual, que excede a imagem em si mesma.

\section{O Arquivo Pedro Meyer}

Feito o login (figura 1), ao entrar no acervo virtual de Pedro Meyer, a primeira tela que se abre organiza suas imagens geograficamente (figura 2). Aí já se tem dimensão da complexidade e da riqueza desse material: trinta e nove países aparecem listados. De algumas nações, como é o caso da Dinamarca, há poucas fotografias - apenas cinco, todas realizadas em uma mesma cidade. Em outras, como o México, local de residência do fotógrafo, mais de cento e oitenta mil imagens são apresentadas, catalogadas de acordo com o estado, a cidade e às vezes até mesmo o bairro em que foram realizadas. Somadas todas as localidades, mais de trezentas mil fotografias, feitas por Meyer ao longo de oito décadas, podem ser assim encontradas. Para além da divisão por território, na barra superior, outras opções de visitação são oferecidas. Por meio delas, é possível percorrer as imagens de acordo com as temáticas pré-definidas, as palavras-chave indexadas ou os personagens nela encontrados. 
Figura 1: Tela de login do Arquivo Pedro Meyer

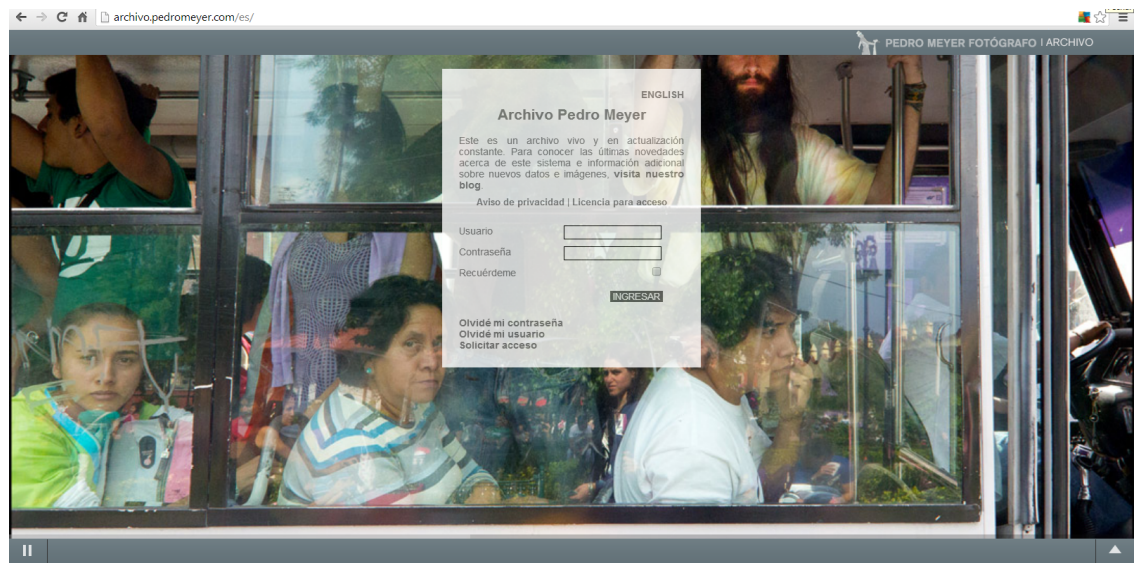

Fonte: archivo.pedromeyer.com

Figura 2: Tela inicial do arquivo, com o acervo disposto geograficamente

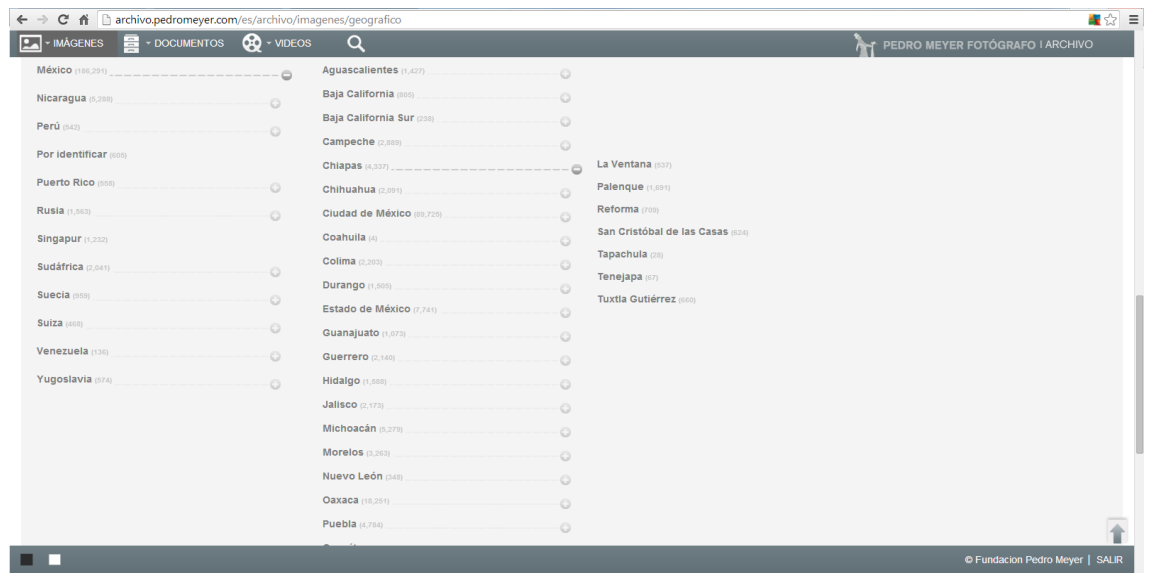

Fonte: archivo.pedromeyer.com 
Os documentos e vídeos, igualmente, estão organizados seguindo os mesmos critérios, em duas abas em separado. A última aba do menu no alto da tela, dá ao usuário a oportunidade de fazer uma busca específica, por conta própria. Para isso, basta digitar uma palavra ou expressão, a partir do qual o servidor procura referências nos objetos catalogados. Na pesquisa, é possível cruzar as referências anteriormente dadas, do tipo de material, dos locais, das temáticas, das palavras-chave ou dos personagens. No caso das fotografias, também é permitido delimitar que os resultados de busca mostrem apenas as imagens com título, publicadas e/ou comentadas. Há ainda como especificar que tipo de fotografias deve ser apresentado na pesquisa, restringindo a imagens originais, editadas e/ou montadas. Pode-se, por qualquer um dos caminhos disponibilizados, chegar às fotografias e aos demais documentos de modo preciso. Ao encontrar um material de interesse e clicar sobre ele, abre-se uma nova tela, na qual o arquivo em questão é apresentado.

Junto com o arquivo aberto, diferentes informações, a depender do tipo de material, são oferecidas no campo de metadados. No caso de uma imagem singular (figura 3), tem-se um identificador, o título, o lugar e a data de captura, a especificação do tipo de fotografia e palavras-chaves com uma indexação que contempla o conteúdo informacional (o que a fotografia mostra) e expressivo (como a fotografia mostra). Sobre isso, se forem observadas as proposições de autores da área de arquivologia, percebe-se que o conteúdo informacional prevalece sobre o expressivo. Embora haja informações sobre o tipo e formato (quase sempre indicando se a fotografia é direta ou se é uma fotomontagem) e a dimensão expressiva da imagem (principalmente sobre o enquadramento e a posição de câmara), elas não são completas. A falta de dados sobre os equipamentos utilizados, as técnicas e recursos empregados, o gênero iconográfico e os detalhes de composição (tempo de exposição, luminosidade, profundidade de tempo, entre outros) torna 
a classificação menos eficiente, pois não dá conta da maneira como o conteúdo é expresso, sobre como ele aparece enquanto registro imagético (SMIT, 1997; MANINI, 2002, et alii).

Além desses dados, a existência de outras versões daquela mesma fotografia e a sua utilização em livros, catálogos de exposição, revistas e artigos são indicadas. Nesse item, os documentos estão inter-relacionados através do recurso de hiperligação. É possível, por exemplo, ir de uma imagem para uma publicação em que ela apareceu. Há, por fim, um hiperlink que leva a uma nova tela, com as demais imagens feitas naquele momento, antes e depois da fotografia em questão (figura 4).

Figura 3: Tela de apresentação de uma fotografia sem título feita em 8 de julho de 1991, em Oaxaca, no México
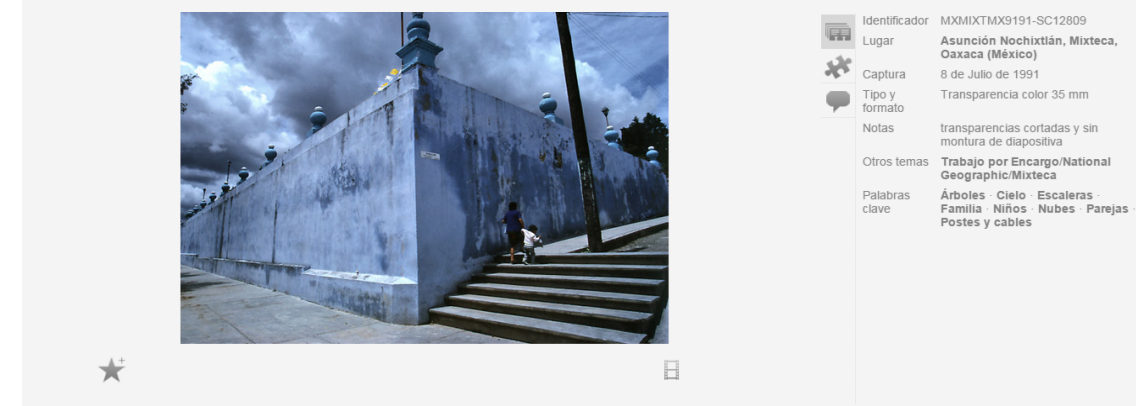

Fonte: archivo.pedromeyer.com 
Figura 4: Tela com sequência de fotografias feitas em 8 de julho de 1991, em Oaxaca, no México

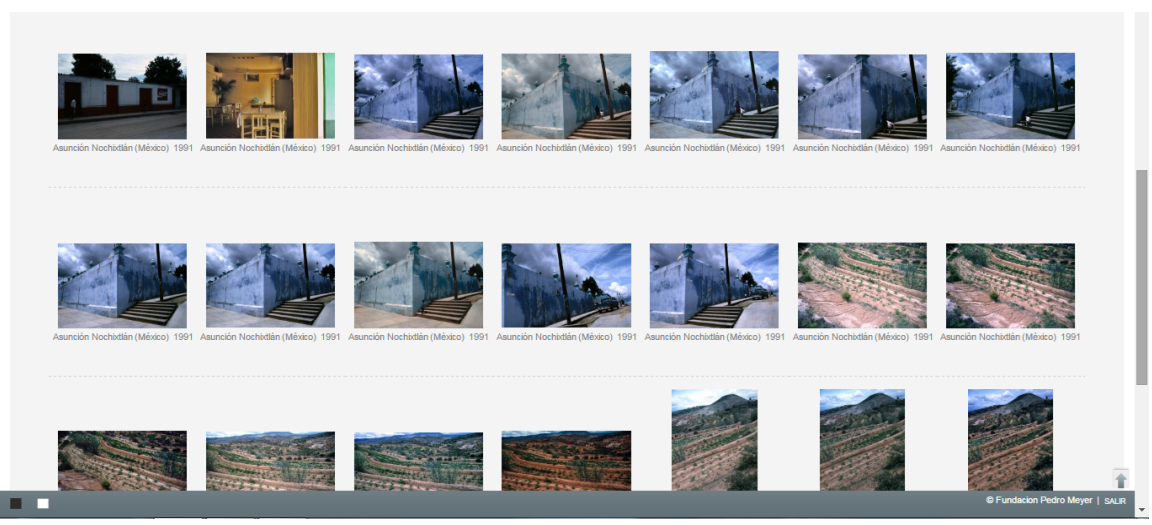

Fonte: archivo.pedromeyer.com

Os livros, catálogos de exposição, revistas, artigos de jornais e vídeos também são dispostos de modo semelhante (figura 5). Além do próprio material, na íntegra, há um identificador, o título da publicação, o nome do autor e, se houver, do(s) colaborador(es), o resumo da obra, o tema nele contemplado, o lugar e a data da publicação, a editora responsável e o formato físico (tamanho e número de páginas ou minutos). Por meio de hiperligações, pode-se ainda ver as imagens contidas nesse material e outras publicações que têm relação temática com ele. 
Figura 5: Tela de apresentação do livro Truths \& fictions

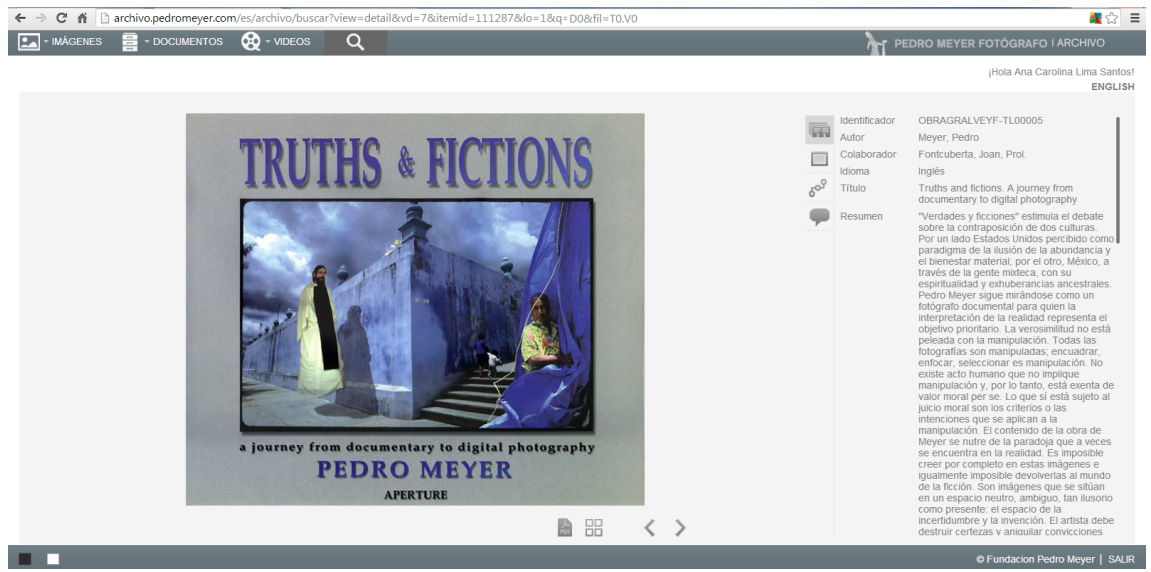

Fonte: archivo.pedromeyer.com

Assim, pulando de link em link, de fotografias a livros, de livros a catálogos, de catálogos a artigos, de artigos a vídeos, de vídeos a outras imagens e delas a suas sequências, tem-se a possibilidade de visitar toda a obra de e sobre Meyer. Trata-se, portanto, de um banco de dados que permite àquele que nele navega conhecer o trabalho do fotógrafo a fundo, por meio de um percurso singular de leitura. Nesse sentido, em termos de formato, o Arquivo Pedro Meyer não se diferencia dos acervos digitais cada vez mais comuns ${ }^{2}$. Todas as vantagens dessas plataformas são compartilhadas pela base de dados do fotógrafo, como o acesso facilitado, independentemente da localização do usuário ou do horário de funcionamento do acervo; rápido retorno de buscas, guiadas ou

2 Nos últimos anos, muitos fundos e coleções fotográficas têm sido disponibilizados na internet. Ao analisar o caso do Brasil, que sequer é um país de referência em tal sentido, nota-se a popularização desse tipo de iniciativa. Aqui, em 2000, de forma pioneira, o Centro de Pesquisa e Documentação em História Contemporânea do Brasil da Fundação Getúlio Vargas (CPDOC/FGV) começou a oferecer acesso online a parte de seu acervo. Atualmente, no site (fgv.br/cpdoc), há mais de oitenta mil fotografias, além de aproximadamente mil vídeos e um milhão de documentos de texto. Seguindo o exemplo do CPDOC, outras instituições criaram acervos virtuais, como a Biblioteca Nacional, a Fundação Casa de Rui Barbosa e o Instituto Moreira Salles (KUSHNIR e HORTA, 2013). 
personalizadas; utilização simultânea do mesmo documento por duas ou mais pessoas, sem qualquer vinculação; mescla de diversos tipos de informação, como fotografias, vídeos e textos, e a criação de conexões entre os materiais, que torna viável ir de um a outro de modo rápido e descomplicado.

Mas, pensando no modo como o banco de dados é concebido, isto é, disponibilizando todo o trabalho fotográfico do artista, algumas especificidades podem ser delineadas. Oferecer acesso a tudo que Meyer fotografou, expôs ou publicou ao longo de sua carreira revela um entendimento particular do fotógrafo sobre sua produção e, a partir dele, convoca-se outra aproximação às imagens realizadas e apresentadas, distinta daquela tradicionalmente concebida pela maioria dos artistas.

\section{A produção e a fruição fotográfica da imagem ao processo}

Ao percorrer o arquivo de Pedro Meyer, é possível ver mais do que as imagens consideradas prontas, finalizadas para serem entregues ao público. Tem-se também a chance de observar, por exemplo, fotografias nunca publicadas em outras plataformas, inclusive aquelas realizadas com centésimos de segundos de diferença das veiculadas como grandes criações do fotógrafo. Pode-se, ainda, chegar às imagens originais, sem qualquer tratamento. Com isso, expondo seu material em estado bruto, apartado da edição, Meyer expõe algo mais: seu próprio processo de criação. Ao dar acesso à totalidade de sua produção por meio do seu acervo virtual, ele revela uma forma própria de lidar com suas imagens, sem se importar que o espectador passe delas ao seu desenvolvimento, aos seus métodos e técnicas de fabricação. Ele se coliga, assim, a um pensamento contemporâneo segundo o qual a arte ganha ao se evidenciar em simultaneidades de ações, não 
linearidades, dinamicidades, experimentações, substituições, adições, deslocamentos e novas associações - em continuidade ou como ruptura (SALLES, 2006).

No banco de dados, ao oferecer a oportunidade de resgatar, na fruição, aquilo que o levou em uma determinada direção (os engajamentos e os acasos construtores, as tentativas e os erros, as simplificações e as dificuldades que permearam a produção), Meyer permite ao público enxergar a imagem como um pensamento em construção, inferindo os mecanismos que o levaram a conformar a imagem daquele jeito e não de outros tantos possíveis, e, com isso, entendendo-a processualmente (SALLES, 1998 e 2006). Assim, o fotógrafo prescreve uma nova maneira de fruir suas obras na medida em que torna visíveis mecanismos quase sempre restritos aos bastidores. Acessar o arquivo de Meyer proporciona uma chance que equivale àquela de olhar todas as folhas de contato, outrora pouco permitida ou desejada pelos produtores .

Assim como nas folhas, no acervo disponibilizado pelo fotógrafo, encontra-se um registro do seu ato fotográfico e uma indicação de seus métodos criativos, desde as estratégias de atuação durante o trabalho de campo até as escolhas de edição. O modo como as folhas de contato eram concebidas pode ser inteiramente subscrito para esse tipo de arquivo:

Oferece-se uma chance única de olhar intimamente para o processo de trabalho do fotógrafo. Está gravado aí cada passo do caminho que se percorre até chegar a uma imagem - proporcionando uma sensação de entrada nos bastidores, de trabalhar lado a lado com o fotógrafo e ver através de seus olhos (LUBBEN, 2011, p. 9, tradução livre).

\footnotetext{
Ainda que o ato de tornar público o que se encontra por trás da obra sempre tenha existido (resultando, por exemplo, em exposições que exibiam folhas de contato, como em The photo essay e Photography as printmark, realizadas respectivamente em 1965 e 1968 pelo Museum of Modern Art of New York, e em documentários com proposta semelhantes, como a série Contacts, lançada entre 1988 e 2001), ele parece ter se intensificado nos últimos anos. Foi apenas entre o final da década de 1990 e início dos 2000 que exposições e publicações que revelam mais dos bastidores da criação, com anotações, esboços e cadernos de artistas se tornaram mais comuns, mas raramente por iniciativa do próprio produtor (LUBBEN, 2011).
} 
Nesse sentido, ao entrar nos bastidores da criação, ao 'ver através dos olhos do fotógrafo', as folhas de contato tanto quanto arquivos como o de Meyer permitem ao espectador moldar um ponto de vista processual sobre uma determinada fotografia, catálogo de exposição ou fotolivro, possibilitando uma nova maneira de se envolver com eles, já que incorpora na fruição o movimento construtivo desses produtos intermediários que o levaram a uma ou outra 'obra pronta'. Tome-se um caso singular (figuras 6 e 7). Ao ver a sequência de uma fotografia tornada célebre, como Good friday (capa de um de seus fotolivros mais aclamados, o Espejo de espinhas, de 1986), por exemplo, pode-se gerar uma interessante percepção da forma como Meyer se aproximou do seu assunto - uma menina que, enquanto é carregada pela mãe durante uma procissão, é coroada com uma grinalda de flores.

Figura 6: Tela de apresentação da fotografia

Good Friday, em versão publicada no livro Espejo de Espinas

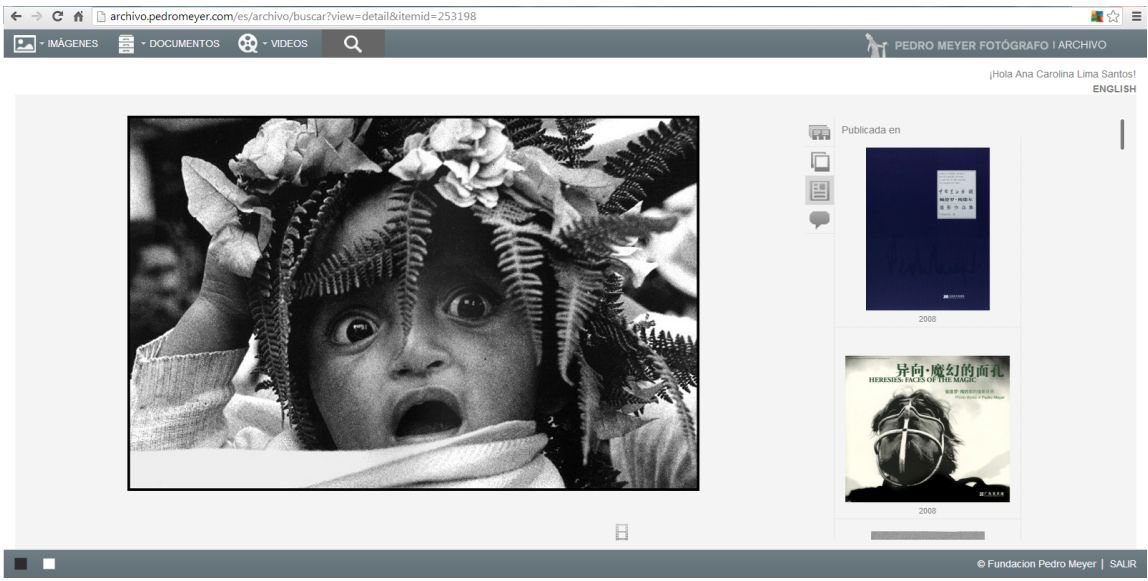

Fonte: archivo.pedromeyer.com 
Figura 7: Tela com sequência de fotografias feitas no mesmo dia de Good Friday, em 29 de setembro de 1984

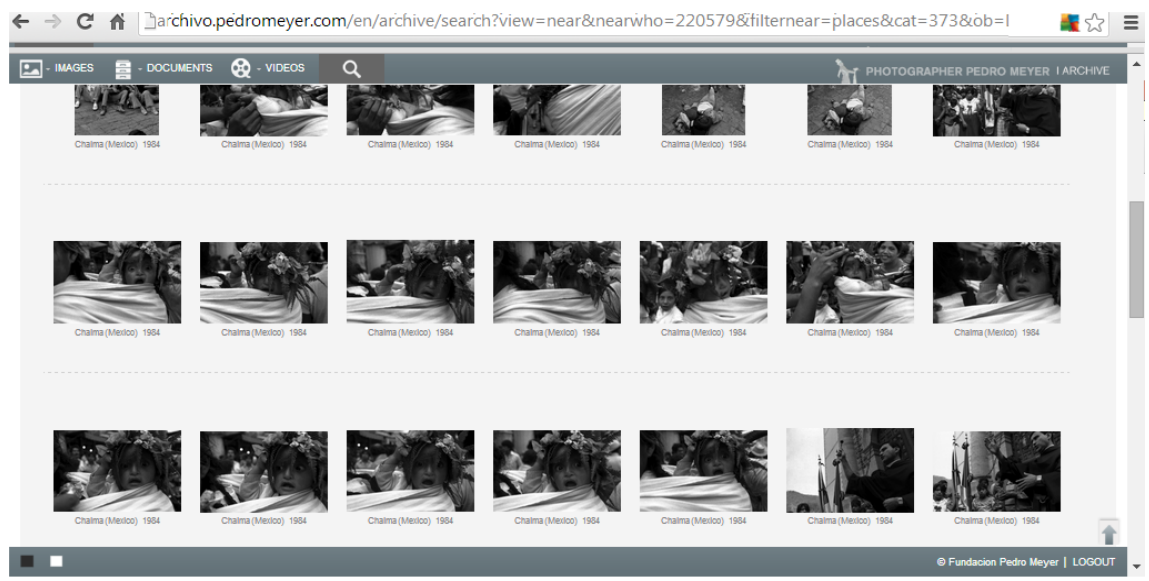

Fonte: archivo.pedromeyer.com

Na produção dessa imagem, nota-se que, ao invés de poupar cliques, assinalando a espera característica do chamado momento decisivo (CARTIER-BRESSON, 1965), Meyer fez muitas fotografias - doze, ao total. Infere-se, com isso, um método de trabalho específico. Ele mesmo, ao falar sobre a captura de outra imagem, revelou que "não tinha intenção de esperar uma semana ou dez dias ou quanto tempo fosse necessário para que algo acontecesse e eu pudesse conseguir um 'momento decisivo' desses tão frequentemente buscados pelos fotógrafos" (MEYER, 1995, p. 115, tradução livre). Assim como nesse caso relatado, em Good friday e em outras tantas imagens, em sua impaciência momentânea, o fotógrafo preferiu eliminar a expectação, fotografando sem esmero aquilo que chamava sua atenção.

Entende-se, ainda, um pouco mais sobre o processo de edição da imagem. A escolha por publicar a fotografia que, mesmo não tendo a melhor composição, dá a ver a criança com uma expressão de maior espanto, indica algo sobre o efeito pretendido por Meyer. O 
mesmo acontece ao perceber que ele reenquadrou o original e aumentou o contraste da imagem na versão publicada no livro, de modo a conferir-lhe mais destaque e dramaticidade. Essas operações, aliás, podem ser percebidas como perpassando uma série de outras ocorrências, sendo constatada como uma prática corriqueira do fotógrafo.

Por outro lado, entender o modo como essa fotografia ou qualquer outra foi criada, mostrando as estratégias mobilizadas do trabalho do campo à edição, pode abrir brecha para diminuir a força ou a potência da fotografia publicada. Como pontuado por alguns fotógrafos, há o receio de que, ao se revelar demais do processo, acabe-se por quebrar o fascínio do espectador. Isso acontece, alegam, sobretudo ao ver outras tentativas que deram 'errado'. A sequência completa de uma imagem "é um diário de experiências, em que se registra, de modo privado, erros, equívocos e enrascadas" (LUBBEN, 2011, p. 10, tradução livre). Por essa lógica, ter acesso a esses erros e equívocos, a imagens desfocadas, com fotometria errada, enquadramentos duvidosos, composições desequilibradas ou outros deslizes técnicos e estéticos (figura 8), tenderia a gerar desencantamentos em relação ao trabalho como um todo. "Como Cartier-Bresson observou, 'uma folha de contato é cheia de rasuras, cheia de detritos. Uma exposição de fotos ou um livro é um convite para uma refeição e não é habitual que os convidados metam o nariz nas panelas e frigideiras"” (Ibidem). 
Figura 8: Tela com sequência de fotografias

feitas em 27 de abril de 2012, em Amsterdã, na Holanda, incluindo erros e equívocos técnicos

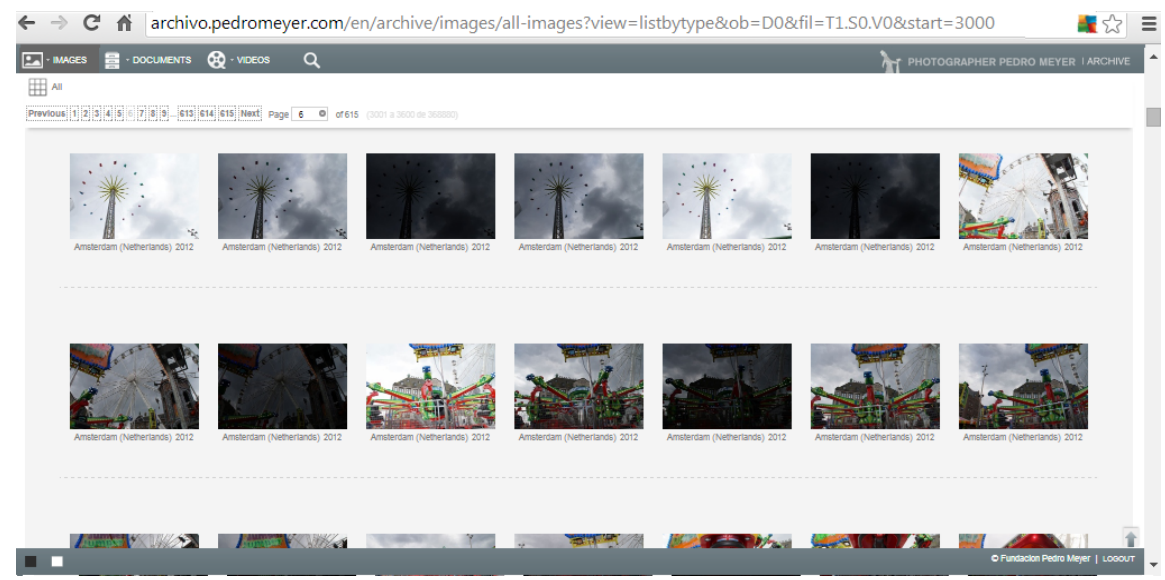

Fonte: archivo.pedromeyer.com

No entanto, ao contrário de Henri Cartier-Bresson e de outros fotógrafos, que não só tinham esse receio de que outros pudessem tomar conhecimento de seus desacertos mas também cuidavam para que isso não acontecesse 4; para Meyer, essa revelação parece não importar. Ele não só fotografa sem cuidado em muitos momentos como não faz questão de esconder isso. A mitificação de uma suposta imagem magicamente realizada, de modo intocável e definitivo, perde sentido. Duas questões são, então, despertadas. A primeira delas diz respeito à concepção do caráter de imagem da fotografia, isto é, de assumi-la como uma construção que necessariamente passa por etapas produtivas que não desmerecem o resultado final - que funciona independentemente do que se tenha feito para chegar nele. A segunda, relacionada a isso, deve-se à ideia de que, justamente por ser construída, uma fotografia nunca está acabada, podendo ser renovada a qualquer momento.

Cartier-Bresson, por exemplo, tinha o costuma de cortar as imagens que considerava interessantes, destruindo o restante das folhas de contato. 
Figura 9: Tela com outras versões de Good Friday, posteriormente publicadas
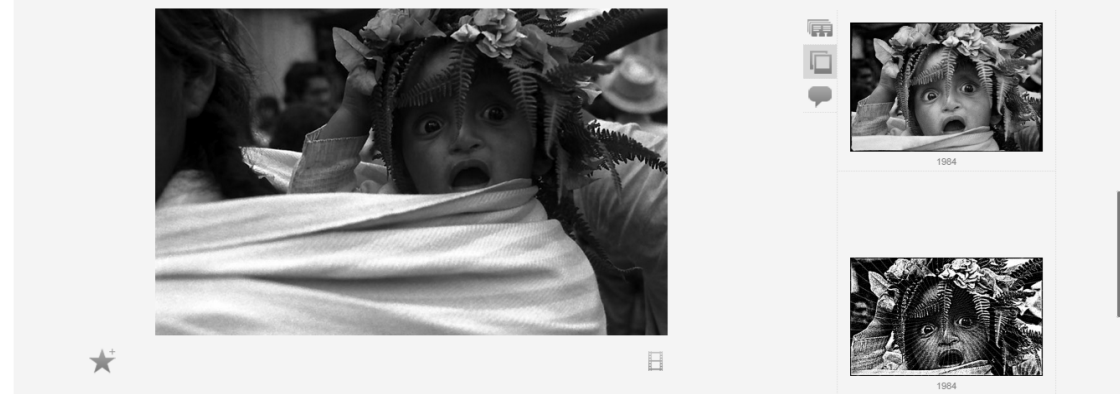

Fonte: archivo.pedromeyer.com

$\mathrm{Na}$ verdade, a natureza explicitamente construída e o inacabamento da fotografia são marcas do trabalho de Meyer. Mesmo quando publicada, para ele, uma imagem pode não estar definitivamente finalizada, podendo ser retomada. Vários são os casos de fotografias que ele publicou mais de uma vez, em diversas versões, às vezes com sutis modificações, outras com alterações bastante significativas (figura 9). A necessidade de esconder a artificialidade da fotografia ou um modo clássico de se ponderar a finalização de uma obra, expresso na ideia de que 'se publica para não passar a vida corrigindo', não condizem com sua visão da atividade fotográfica e com o que ele acaba pondo em prática. Nesse sentido, ao exibir seus processos, talvez Meyer não empobreça a imagem ou o encantamento que ela seria capaz de produzir, como temiam alguns, mas enriqueça a fotografia na medida em que possibilita que ela seja reintegrada e ressignificada pelos seus métodos de fabricação. Ao incorporar as dimensões de um fazer fotográfico que, em sua infinitude e incompletude artísticas, o 
fotógrafo eleva as possibilidades de apropriação, hibridação e transformação das imagens, das boas e das ruins, das certas e das erradas, do arquivo como um todo. Mais que isso, ele condiciona suas imagens a potencialização da sensibilidade do olhar - dele, que as produz, e do espectador, que as frui.

Esse é, também, o motivo e o motivador das manipulações digitais de Meyer, pelas quais ficou conhecido a partir da década de 1990, mais especificamente com o lançamento do livro Truths \& fictions, em 1995. Para fazer suas montagens, o fotógrafo tem partido de imagens, muitas vezes já publicadas anteriormente, que são reinterpretadas e reconfiguradas. Em muitos casos (figura 10), dois ou mais negativos distintos são mesclados em um único quadro, dando origem ao que chama de instante digital - que engloba procedimentos de pós-produção distintos, realizados com o auxílio do computador, extensão da câmera e segundo 'quarto escuro' (GREEN, 1995). Os registros iniciais servem, então, menos como produtos derradeiros que como anotações e observações a serem revisadas, reformuladas e recriadas, em uma atitude contrária àquela pregada por Henri Cartier-Bresson, segundo o qual a realidade deveria ser percebida simultaneamente ao seu registro, no calor do momento, não podendo ser posteriormente reconstruída pelo fotógrafo (CARTIER-BRESSON, 1965). Nesse sentido, perceber a imagem original como errada ou incompleta não é um problema, uma vez que ela sempre pode ser submetida a outras operações, legítimas e eficazes. 
Figura 10: Tela de apresentação da imagem Virgil in the greased pole, publicada no livro Truths \& fictions, evidenciando os negativos que a compõem

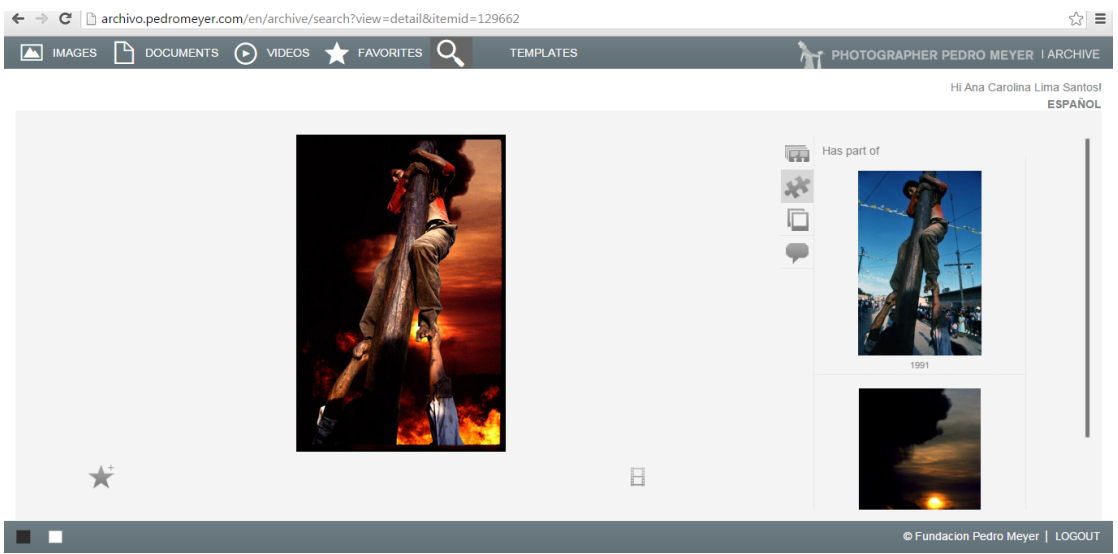

Fonte: archivo.pedromeyer.com

Em alguns casos, esse método inclui até mesmo retomar montagens anteriores como parte do quadro de uma nova imagem (figuras 10 e 11), complexificando o caráter provisório de suas intervenções. Se é verdade, como nos lembra Mauricio Lissovsky (2011), apropriando-se das proposições de Walter Benjamin, que o arquivo fotográfico é sempre infinito em todas as direções e incompleto em todos os momentos, nele podendo a imagem se conjugar no futuro do pretérito; o fotógrafo torna mais forte a percepção dessa infinitude e dessa incompletude a partir da publicização do seu arquivo, inteiramente, como na base de dados, ou parcialmente, como nas versões e montagens parciais que publica. Tomando e evidenciando a fotografia (original ou manipulada, primeiramente publicada ou posteriormente renovada) sempre como hipótese, como incerteza ou como irrealidade, ele assim a conjuga e igualmente sugere isso a quem a vê. 
Figura 11: Tela de apresentação da imagem The case of the missing painting, montada a partir de Virgil in the greased pole e outros dois negativos
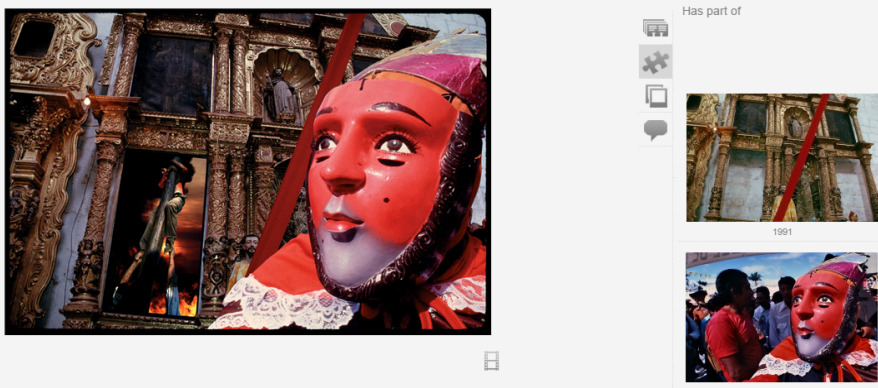

Fonte: archivo.pedromeyer.com

\section{Considerações finais}

O Arquivo Pedro Meyer foi criado inicialmente como ferramenta para organizar a produção fotográfica do artista e permitir a execução de um projeto coletivo de retrospectiva organizado pelo próprio Meyer. Cumprido esse objetivo pontual, a base de dados logo foi tornada acessível a outras pessoas, dando-lhes a oportunidade de conhecer e pesquisar melhor sobre os trabalhos produzidos pelo fotógrafo. No arquivo, mais de trezentas mil imagens, além de livros e catálogos de exposição feitos por Meyer e de revistas, artigos de jornais e vídeos realizados por ou sobre ele, estão organizados, catalogados, inter-relacionados e disponíveis para consulta. Mas, longe de ser um acervo comum, essa base de dados traz uma especificidade cuja vitalidade pareceu merecer atenção: nele, pode-se ver toda a produção do fotógrafo em estado bruto, sem filtro dele ou de outros mediadores. 
Debruçando-se sobre tal particularidade, este artigo evidenciou que a disponibilização do acervo de Meyer dessa maneira revela uma concepção do fotógrafo em relação ao caráter de uma obra (compreendida como inacabada e incompleta) e que, consequentemente, pede ao espectador para se posicionar diante dela de modo semelhante (entendendo-a como um pensamento em construção). Assim, no arquivo, a produção e a fruição podem passar da imagem como um ponto de convergência ou um resultado final para chegar ao processo, percebido como elemento fundante ou como produto em si mesmo. Nessa perspectiva processual, é possível enxergar que a partilha de sensibilidades que envolve o fotógrafo e o público pode se instaurar nos métodos e técnicas de fabricação tanto quanto das imagens que restam deles. Ao se diminuir os espaços que separam a fotografia de sua constituição, o processo de criação que se revela a partir de visualização do banco de dados implica e é implicado em sua fruição, abrindo-se a ela a possibilidade de ser iluminada pela descoberta do projeto que guia o artista e sua obra.

\section{Referências bibliográficas}

CARTIER-BRESSON, Henri. "O momento decisivo". In: Bloch Comunicação, n. 6. Rio de Janeiro: Bloch Editores, 1965.

GREEN, Jonathan. "Pedro Meyer's special theory of relativity". In: MEYER, Pedro (org). Truths \& fictions's gallerie. Coyoacán: Fundación Pedro Meyer, 1995. Disponível em: www.pedromeyer.com/galleries/truths/state.html. Acesso em 02/07/2009. 
KUSHNIR, Beatriz; HORTA, Sandra (org). "Dossiê Workshop de Acervos Fotográficos". In: Revista do Arquivo Geral da Cidade do Rio de Janeiro, n. 7. Rio de Janeiro: Arquivo Geral da Cidade do Rio de Janeiro, 2013.

LISSOVSKY, Maurício. "Dez proposições acerca do futuro da fotografia e dos fotógrafos do futuro". In: Facom, v. 23. São Paulo: Fundação Armando Álvares Penteado, 2011.

LUBBEN, Kristen. Magnum contact sheets. London: Thames \& Hudson Ltd, 2011.

MANINI, Miriam. Análise documentária de fotografias: um referencial de leitura de imagens fotográficas para fins documentários. Brasília: Programa de Pós-Graduação em Ciência da Informação da UnB, 2002.

MEYER, Pedro. Truths \& fictions: a journey from documentary to digital photography. New York: Aperture, 1995.

SALLES, Cecília. Gesto inacabado: processo de criação artística. São Paulo: Annablume, 1998.

SALLES, Cecília. Redes de criação: construção da obra de arte. Vinhedo: Editora Horizonte, 2006.

SMIT, Johanna. "Propostas para a indexação de informação iconográfica”. In: Anais do Info'97. Havana: Congresso Internacional de Informática, 1997. 